Received 19th August 2019,

Accepted 3rd September 2019

DOI: $10.1039 / c 9 d t 03379 c$

rsc.li/dalton

\section{Diastereoselective diazenyl formation: the key for manganese-catalysed alcohol conversion into $(E)$-alkenes $\uparrow$}

\author{
Luis Miguel Azofra (D) *a,b and Albert Poater (D)*c
}

\section{Introduction}

At the forefront of the design and synthesis of novel homogeneous catalysts, manganese ${ }^{1}$ occupies a central place given the large number of applications that have been reported in the recent years. ${ }^{2}$ Together with its versatility, manganese is postulated as a perfect candidate for the development of alternative homogeneous materials given its low-price, abundance, and non-toxicity. ${ }^{3}$

In 2016, Milstein reported a set of well-defined Mn(I) complexes bearing PNP ligands capable of catalyse a series of hydrogenation/dehydrogenation reactions, such as Michael addition of aliphatic nitriles to $\alpha, \beta$-unsaturated carbonyl compounds ${ }^{4}$ or the dehydrogenative coupling of alcohols and imines to form aldimines. ${ }^{5}$ In the context of metal-ligand cooperation (MLC) catalysis, the postulated reaction mechanism considered the participation of the non-innocent pincer ligand in a cycle constituted by successive aromatisation and dearomatisation steps. This mechanistic approach has also been proposed by Kirchner et al. for the coupling of alcohols

\footnotetext{
${ }^{a}$ CIDIA-FEAM (Unidad Asociada al Consejo Superior de Investigaciones Cientificas, CSIC, avalada por el Instituto de Ciencia de Materiales de Sevilla, Universidad de Sevilla), Instituto de Estudios Ambientales y Recursos Naturales (i-UNAT), Universidad de Las Palmas de Gran Canaria (ULPGC), Campus de Tafira, 35017 Las Palmas de Gran Canaria, Spain. E-mail: luismiguel.azofra@ulpgc.es

${ }^{b}$ Departamento de Quimica, Universidad de Las Palmas de Gran Canaria (ULPGC), Campus de Tafira, 35017 Las Palmas de Gran Canaria, Spain

${ }^{c}$ Institut de Química Computacional i Catàlisi, Departament de Quimica, Universitat de Girona, c/M $M^{a}$ Aurèlia Capmany 69, 17003 Girona, Catalonia, Spain.

E-mail: albert.poater@udg.edu

$\dagger$ Electronic supplementary information (ESI) available: Supporting computational results. See DOI: 10.1039/c9dt03379c
}

and amines into imines, ${ }^{6}$ and by Milstein and co-workers for the coupling of hydrazones from alcohols and hydrazine, ${ }^{7}$ amongst other examples. ${ }^{8,9}$

Other catalytic applications, also within the MLC perspective, are founded on the role played by bifunctional catalysts containing the $[\mathrm{Mn}-\mathrm{N}]$ motif: while $\mathrm{N}$ behaves as a Lewis base centre, manganese has an electrophilic character, promoting the respective proton and hydride borrowing in processes where (de)-hydrogenation is the catalytic target or a fundamental stage along the mechanism. In this sense, Beller and coworkers reported the selective hydrogenation of ketones, aldehydes, esters, and nitriles, ${ }^{10,11}$ as well as $\mathrm{N}$-alkylation of amines with alcohols. ${ }^{12}$ A similar research carried out by Kempe reported the employment of a novel Mn complex bearing a $\mathrm{PN}_{5} \mathrm{P}$ ligand that displays a broad capacity to efficiently hydrogenate $\mathrm{C}=\mathrm{O}$ bonds. ${ }^{13}$ This new generation of Mn complex was also satisfactorily applied for the multicomponent synthesis of pyrimidines. ${ }^{14}$ Important advances have also been carried out by Rueping and co-workers, describing unprecedented chemoselective hydrogenation of internal alkynes into (Z)-alkenes by a Mn(I)-PNP hydride, ${ }^{15}$ or the generation of "green" methanol by hydrogenation of $\mathrm{CO}_{2}$-derived (poli)-carbonates using well-defined Mn(I)-NNP complexes that work at milder conditions of pressure and temperature. ${ }^{16}$ Definitively, these are just a few instances amongst the plethora of organic transformations catalysed by manganese that have been reported in the last lustrum. ${ }^{17-26}$

Encouraged by our interests in the unravelling of the mechanistic aspects in the catalytic chemistry of manganese, ${ }^{27-30}$ the recent work by Milstein et al. ${ }^{31}$ reporting for first-time a manganese-catalysed coupling of alcohols and hydrazone to form alkenes, caught our attention. As an 


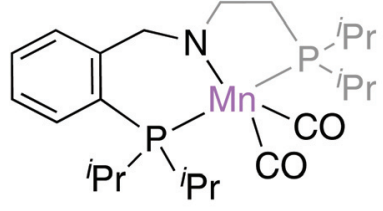

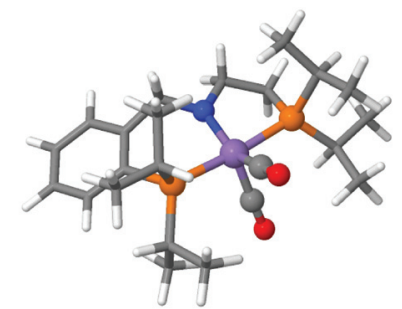

Fig. 1 Kekule and optimised structures for the 16e species (A). For clarity, only atoms surrounding $\mathrm{Mn}$ are represented using balls and sticks, while for the rest only sticks.

alternative to the classical approaches for the synthesis of olefins from carbonyl compounds (such as Wittig, ${ }^{32}$ Peterson, ${ }^{33}$ or Julia ${ }^{34}$ olefinations), Milstein and co-workers offer an unprecedented base- and waste-free procedure for the direct transformation of alcohols into alkenes. Despite the impact of this finding on the organometallic catalytic chemistry, the reaction mechanism for this process remains unknown.

With the aim of shedding light on this, we have carried out a detailed DFT study analysing the catalytic role that plays the most active $\mathrm{Mn}\left({ }^{\mathrm{i}} \mathrm{Pr}-\mathrm{PNP}\right)(\mathrm{CO})_{2}$ amido complex (see Fig. 1), as reported in Milstein's work. ${ }^{31}$ This 16e species has a trigonal bipyramidal geometry with phosphorus atoms in axial dispositions and nitrogen and $\mathrm{CO}$ ligands in equatorial. As previously indicated, the $\mathrm{Mn}-\mathrm{N}$ bond exhibits a dual role, with $\mathrm{Mn}$ and $\mathrm{N}$ behaving as electrophilic and nucleophilic centres, respectively. The hydrogenation of the $\mathrm{Mn}-\mathrm{N}$ bond by acceptorless dehydrogenation of an alcohol $\mathrm{RCH}_{2} \mathrm{OH}$ would generate the 18e species $[\mathrm{MnH}-\mathrm{NH}]$ and an aldehyde. In an excess of hydrazine, this would produce a hydrazone compound $\mathrm{RCHN}=\mathrm{NH}_{2}$ plus the release of a $\mathrm{H}_{2} \mathrm{O}$ molecule. After regeneration of the 16 e species $[\mathrm{Mn}-\mathrm{N}]$ by dehydrogenation of the $18 \mathrm{e}$ species, the hydrazone would react to produce a $\mathrm{N}-\mathrm{H}$ active species, being this nitrogen a stereocentre. Based on experiments, $\mathrm{Mn}\left({ }^{\mathrm{i}} \mathrm{Pr}-\right.$ $\mathrm{PNHP})(\mathrm{NHN}=\mathrm{CHR})(\mathrm{CO})_{2}$ is a stable entity and has been characterised by NMR, IR, and X-ray techniques. This species has served as a reference to build the initial guesses that will define those minima and transition states (TS) of the reaction mechanism proposed in the present research. Coming into play the already formed aldehyde, a condensation reaction would take place generating two additional carbon stereocentres. Four potential diastereoisomers of diazenyl intermediate would be therefore generated, i.e., $\left(S_{\mathrm{N}}, S, S\right),\left(S_{\mathrm{N}}, R, S\right),\left(S_{\mathrm{N}}, S, R\right)$, and $\left(S_{\mathrm{N}}, R, R\right)$ (or their enantiomeric pairs), imposing stereoselectivity towards the formation of a $(Z)$ - or $(E)$-alkene once decomposed and liberating $\mathrm{N}_{2}$ and $\mathrm{H}_{2} \mathrm{O}$ as the only by-products (Scheme 1).

\section{Computational details}

The reaction mechanism for the direct transformation of primary alcohols into alkenes catalysed by $\mathrm{Mn}(\mathrm{I})$-PNP com-

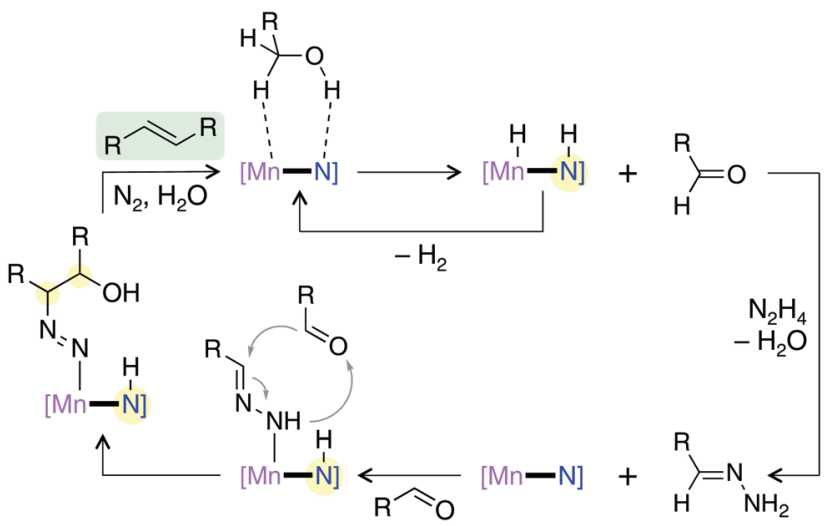

Scheme 1 Reaction mechanism overview. Atoms highlighted in yellow refer to stereocentres.

plexes has been studied through the use of Density Functional Theory (DFT) via the spin-restricted Kohn-Sham (RKS) formalism and the BP86 functional. ${ }^{35,36}$ The split-valence SVP basis set was used for non-metal atoms while the triple- $\xi$ TZVP basis set was employed for $\mathrm{Mn} .{ }^{37}$ In all cases, frequency calculations were performed in order to confirm the nature of the stationary points (minima or first-order TSs with one imaginary frequency). In order to obtain more accurate energy values, single-point energy refinement calculations in solvent have been performed over previously optimised structures at the $\mathrm{PBE0}^{38} / \mathrm{TZVP}$ level of theory, including Grimme's D3 dispersion corrections. ${ }^{39}$ For the purpose of simulate the solvent effect, the Solvation Model based on Density (SMD) ${ }^{40}$ has been used with the standard parameters for THF $(\varepsilon=7.6)$. Gibbs free energies have been computed at $120{ }^{\circ} \mathrm{C}$ and atmospheric pressure reaction conditions. All calculations were carried out using a fine grid and through the facilities provided by the NWChem package (version 6.8). ${ }^{41}$

\section{Results and discussion}

The mechanism for the Mn-catalysed direct conversion of primary alcohols into alkenes by dehydrogenative coupling with hydrazine can be posed as a process constituted by two main cycles, namely alcohol dehydrogenation (AD) and alkene formation $(\mathrm{AF})$. For the purpose of the modelling, phenylmethanol has been selected as model substrate.

In the first, the Mn-PNP complex (16e species, A) catalyses the acceptorless dehydrogenation of the alcohol into an aldehyde (Fig. 2). Two plausible pathways can be proposed: stepwise, in which proton and hydride are transferred sequentially, or through a concerted way, where both are transferred simultaneously.

As it has been previously reported in similar homogeneous catalysts, ${ }^{16,28}$ proton transfer from the hydroxyl group in the alcohol to the $\mathrm{N}$ in the catalyst is hypothesised as a barrier-less process for the step-wise mechanism (see Fig. S1 at the ESI $†$ ). As result of this, a Mn-alkoxy complex is generated (B), being 


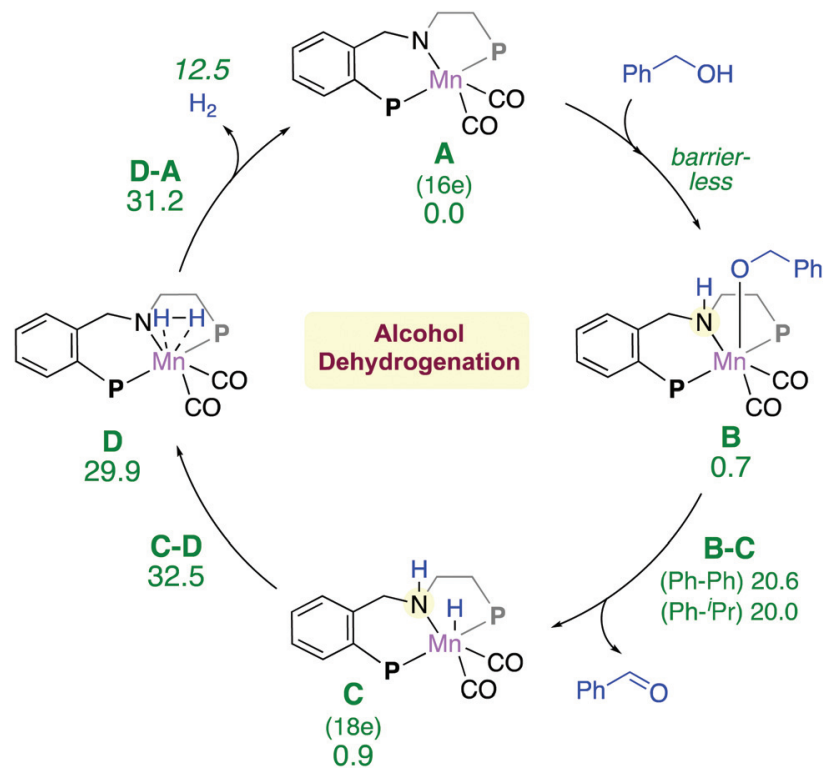

Fig. 2 Reaction mechanism for alcohol dehydrogenation (AD) into aldehyde catalysed by a $\mathrm{Mn}(\mathrm{I})-\mathrm{PNP}$ catalyst. Free energy results (1 atm, $\left.120^{\circ} \mathrm{C}\right)$ are shown at the PBEO + D3/TZVP//BP86/TZVP(Mn)-SVP(H,C,N, $\mathrm{O}, \mathrm{P})$ level of theory in THF as solvent. Atoms highlighted in yellow refer to stereocentres. For clarity, $\mathrm{P}$ refers to $\mathrm{P}\left({ }^{\mathrm{i}} \mathrm{Pr}\right)_{2}$.

at $0.7 \mathrm{kcal} \mathrm{mol}^{-1}\left(1 \mathrm{~atm}, 120{ }^{\circ} \mathrm{C}\right.$ reaction conditions). Although the already formed amino $\mathrm{N}^{*}(\mathrm{H})$ atom becomes a stereocentre, this has no consequences from the point-of-view of the selectivity at this stage of the reaction. For the subsequent hydride transfer, two different TSs are located based on the orientation of the phenyl group in the alkoxy moiety. This transfer $(\mathbf{B}-\mathbf{C})$ takes place from the $\mathrm{C}\left(\mathrm{sp}^{3}\right)$ in the alkoxy to the manganese, and barriers are calculated in 20.6 and $20.0 \mathrm{kcal} \mathrm{mol}^{-1}$ for the cases in which phenyl-phenyl and phenyl-iso-propyl groups are faced (see Fig. 3). In both cases, $\mathrm{C}\left(\mathrm{sp}^{3}\right)$-hydride distances are $c a .1 .7 \AA\left(1.71 \AA\right.$ for $\mathrm{Ph}-\mathrm{Ph}$ and $1.70 \AA$ for $\left.\mathrm{Ph}^{\mathrm{i}} \mathrm{Pr}\right)$, so the small difference between the calculated activation energies seems to be due to very minor effects, principally steric. With the release of benzaldehyde at $\mathbf{C}$, the hydrogenated $18 \mathrm{e}$ species $[\mathrm{MnH}-\mathrm{NH}]$ is formed, showing an increase in the $\mathrm{Mn}-\mathrm{N}$ bond of $0.28 \AA$ with respect the $16 \mathrm{e}$ species $[\mathrm{Mn}-\mathrm{N}](1.90 \AA)$. This, together with a Mayer Bond Order analysis, suggests the complete single character of the $\mathrm{Mn}-\mathrm{N}$ bond in $\mathbf{A}(0.997$ for $\mathbf{A}$ to be compared with 0.447 for $\mathbf{C}$ ). In addition, triplet states in $\mathbf{A}$ and C species have been calculated to be 23.5 and $46.2 \mathrm{kcal} \mathrm{mol}^{-1}$ less favoured than single states, unambiguously indicating that the reactivity takes place in the singlet state.

We were also able to identify a concerted mechanism for alcohol dehydrogenation (A-C). With a similar trend but presenting longer energy differences, the TS in which phenyl and iso-propyl groups are faced exhibits a less endergonic barrier of $16.1 \mathrm{kcal} \mathrm{mol}^{-1}$ than the so-called $\mathrm{Ph}-\mathrm{Ph}$ maximum (18.9 kcal mol${ }^{-1}$ ) (see Fig. 3). In any case, free energy results clearly indicate the preference in the acceptorless dehydrogenation to proceed via a concerted mechanism in which
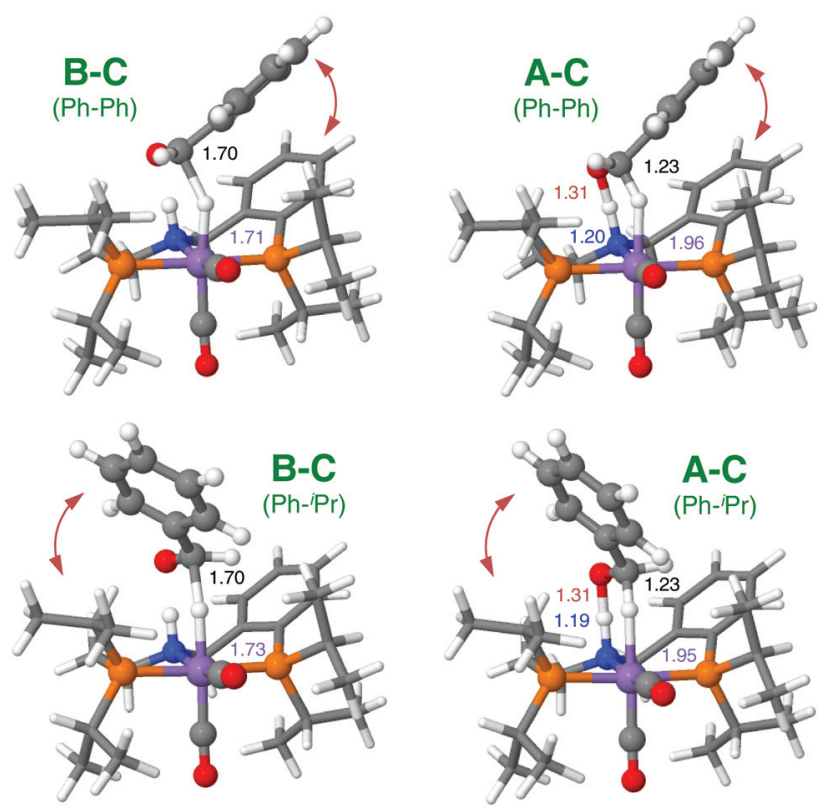

Fig. 3 Optimised structures for B-C and A-C TSs, indicating the hydride and $\mathrm{H}_{2}$ transfers in the step-wise and concerted mechanisms for AD cycle. Selected $\mathrm{O}-\mathrm{H}$ (red), $\mathrm{N}-\mathrm{H}$ (blue), $\mathrm{C}-\mathrm{H}$ (black) and $\mathrm{Mn}-\mathrm{H}$ (purple) distances are shown in $\AA$.

proton and hydride are simultaneously transferred from the alcohol to the bifunctional $\mathrm{Mn}-\mathrm{N}$ moiety.

Once generated the $18 \mathrm{e}$ species $[\mathrm{MnH}-\mathrm{NH}]$, its dehydrogenation is imperative for the cross-coupling reaction.

This process was calculated and shows a very high activation of $32.5 \mathrm{kcal} \mathrm{mol}^{-1}$ (C-D). We failed in all our attempts to find a TS assisted by a bridging $\mathrm{H}_{2} \mathrm{O}$ molecule, however, an assisted TS by a bridging phenylmethanol molecule was located, decreasing the barrier to $29.6 \mathrm{kcal} \mathrm{mol}^{-1}$. As final stage closing this first cycle of alcohol dehydrogenation (AD), $\mathrm{H}_{2}$ is released and the 16e species [Mn-N] is regenerated. For this, a barrier of $31.2 \mathrm{kcal} \mathrm{mol}^{-1}$ has been estimated.

During the second cycle of alkene formation (AF), in an excess of hydrazine, benzadelhyde could be transformed into hydrazone, as it was already reported by Milstein and colleagues. ${ }^{7}$ The generated hydrazone $\mathrm{PhCHN}=\mathrm{NH}_{2}$ interacts with the $16 \mathrm{e}$ species $[\mathrm{Mn}-\mathrm{N}]$ transferring one of the two protons from the $\mathrm{NH}_{2}$ moiety to the nucleophilic $\mathrm{N}$ in the catalyst. This proton cession has also been calculated as a barrierless process. As a result of this, the reference $\mathrm{Mn}\left({ }^{\mathrm{i}} \mathrm{Pr}-\mathrm{PNHP}\right)$ $(\mathrm{NHN}=\mathrm{CHPh})(\mathrm{CO})_{2}$ species is formed $(\mathbf{E})$, being linked through a Mn-N bond with a distance of $2.06 \AA$ and $-0.7 \mathrm{kcal} \mathrm{mol}^{-1}$ of reaction energy (relative to A plus hydrazone, $7.8 \mathrm{kcal} \mathrm{mol}^{-1}$ ). As occurred in the first cycle, the activation of $\mathrm{N}$ via the generation of a $\mathrm{N}-\mathrm{H}$ bond makes that $\mathrm{N}$ becomes a stereocentre. For the purposes of this discussion, a $(S)$ configuration is assumed, referring to it as $\left(S_{\mathrm{N}}\right)$ to indicate the chirality in an atom different to carbon. From a mechanistic point-of-view and as clearly indicated along Fig. 4, for this second cycle, the proton transfer does not obey to a proper 


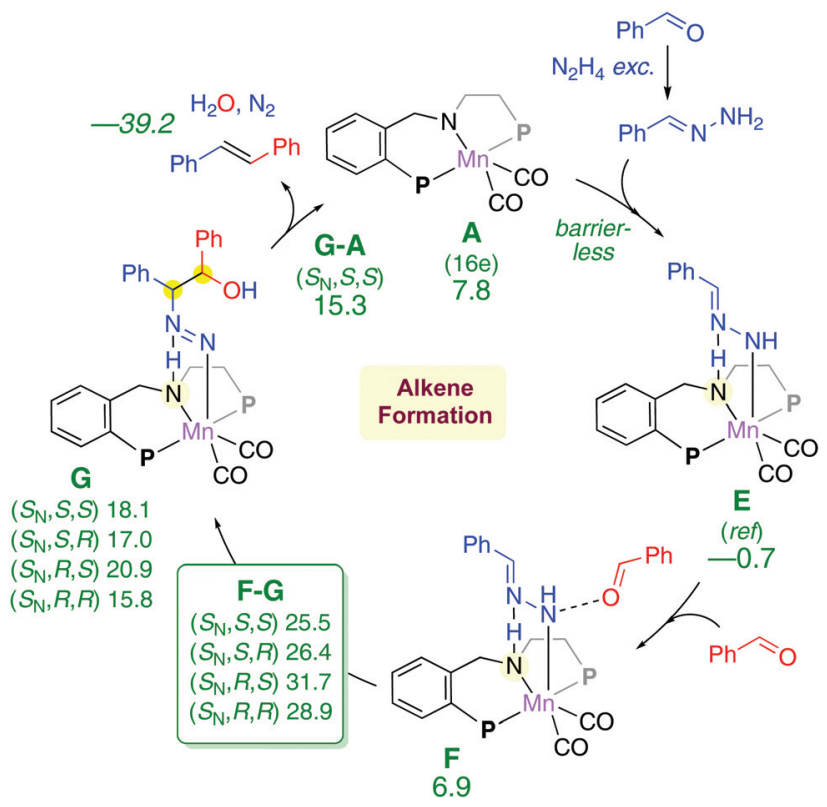

Fig. 4 Reaction mechanism for alkene formation (AF) catalysed by a $\mathrm{Mn}$ (I)-PNP catalyst. Free energy results $\left(1 \mathrm{~atm}, 120^{\circ} \mathrm{C}\right)$ are shown at the PBEO + D3/TZVP//BP86/TZVP(Mn)-SVP(H,C,N,O,P) level of theory in THF as solvent. Atoms highlighted in yellow refer to stereocentres. For clarity, $\mathrm{P}$ refers to $\mathrm{P}(\mathrm{P} \mathrm{Pr})_{2}$.

acceptorless dehydrogenation of the hydrazone. Contrary to what has been described for $\mathrm{AD}$ cycle, the catalyst exerts a role of proton borrowing during the process. Benzaldehyde, which has been produced along the precedent $\mathrm{AD}$ cycle, approaches to $\mathbf{E}$ in order to be subsequently incorporated in a formal condensation reaction. Transition states $\mathbf{F}-\mathbf{G}$ describes this fundamental mechanistic step. First, the coupling of the $\mathrm{sp}^{2}$ carbons from $[\mathrm{NHN}=\mathrm{CHPh}]^{-}$and benzaldehyde is promoted by an electronic reorganisation, with the proton in $[\mathrm{NHN}=\mathrm{CHPh}]^{-}$ being transferred to the $\mathrm{C}=\mathrm{O}$ functionality in benzaldehyde (Fig. 5). This process, in which the metal centre does not participate directly but has a cooperative effect, promotes the formation of a C-C bond in which both become stereocentres. As a consequence of this coupling, four plausible TSs can be described: $\left(S_{\mathrm{N}}, S, S\right),\left(S_{\mathrm{N}}, R, S\right),\left(S_{\mathrm{N}}, S, R\right)$, and $\left(S_{\mathrm{N}}, R, R\right)$ (or their enantiomeric pairs). In other words, having formed the $\mathrm{N}^{*}(\mathrm{H})$ centre with $\left(S_{\mathrm{N}}\right)$ configuration at step $\mathbf{E}$, depending on which enantioface are pointing the phenyl groups, the incipient formation of $(S)$ or $(R)$ carbon stereocentres might lead to a diastereoselective formation of a diazenyl intermediate. Based on free energy results, TS $\left(S_{\mathrm{N}}, S, S\right)$ [more properly referred to as $\left(S_{\mathrm{N}}\right.$, pro-S,pro-S $\left.)\right]$ exhibits the lowest activation with $25.5 \mathrm{kcal}$ $\mathrm{mol}^{-1}$. For the $\left(S_{\mathrm{N}}, R, S\right),\left(S_{\mathrm{N}}, S, R\right)$, and $\left(S_{\mathrm{N}}, R, R\right)$ cases, barriers have been calculated as $31.7,26.4$, and $28.9 \mathrm{kcal} \mathrm{mol}^{-1}$, respectively. Further, to emphasise the role of stabilisation between aromatic rings in the TS $\mathbf{F}-\mathbf{G}$, we plot the noncovalent interactions (NCI), calculated using the NCIplot program developed by Contreras-García. ${ }^{42,43}$ NCI plots in Fig. 6 show more attractive (in blue) non-covalent interactions ${ }^{29,44}$ than repulsive ones (in red) between the entering ketone substrate and the
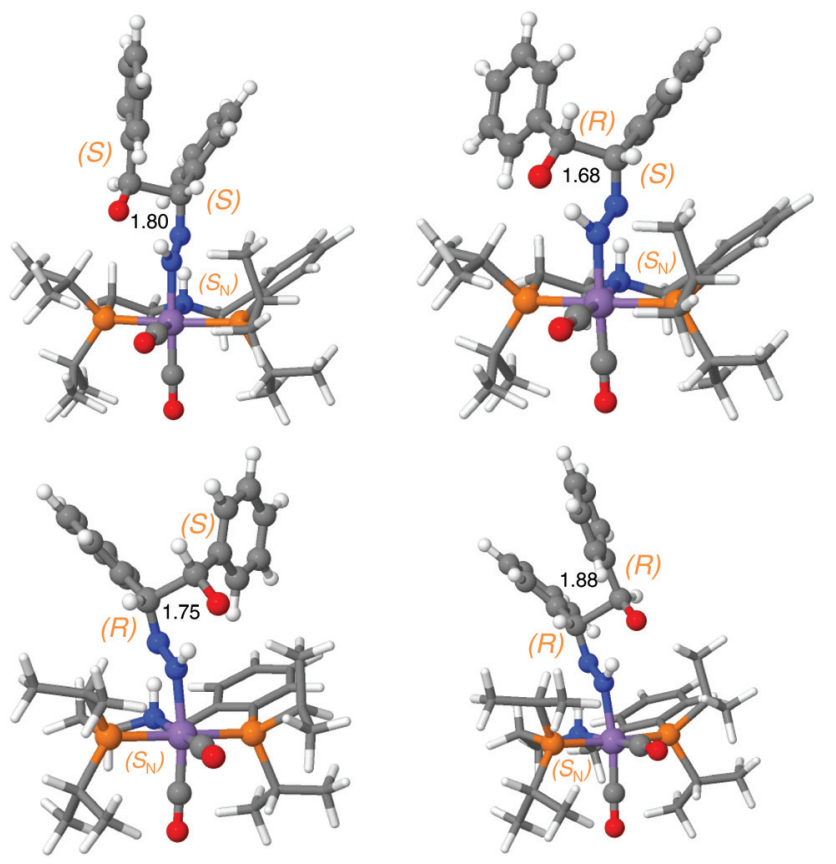

Fig. 5 From left to right and top to bottom, optimised structures for F$\mathrm{G}$ TSs in AF cycle, corresponding to $\left(S_{\mathrm{N}}, S, S\right),\left(S_{\mathrm{N}}, S, R\right),\left(S_{\mathrm{N}}, R, S\right)$, and $\left(S_{\mathrm{N}}, R\right.$, $R$ ) cases. Selected C-C (black) distances are shown in $\AA$.
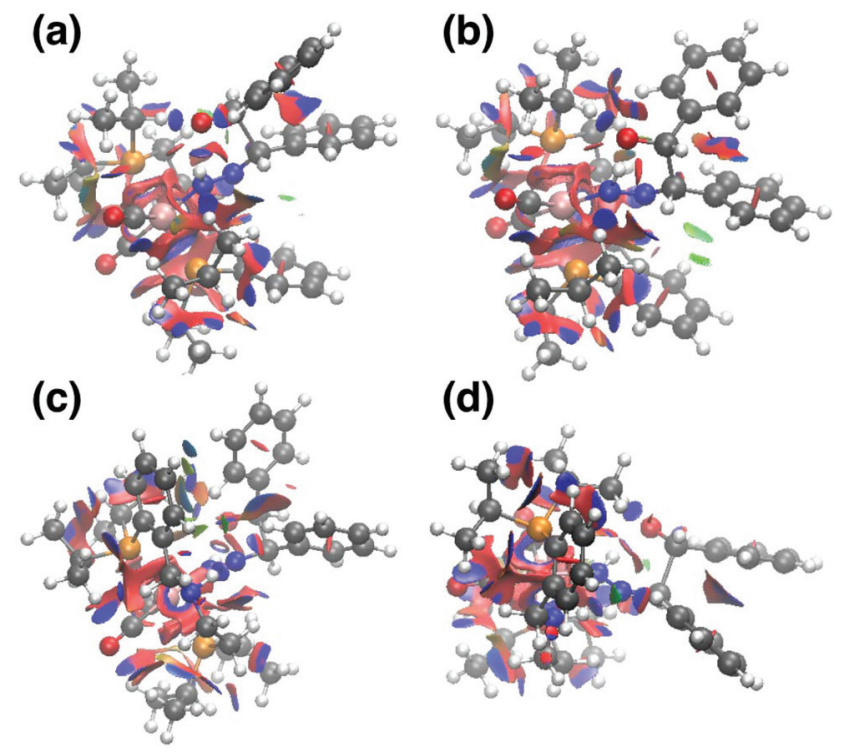

(d)

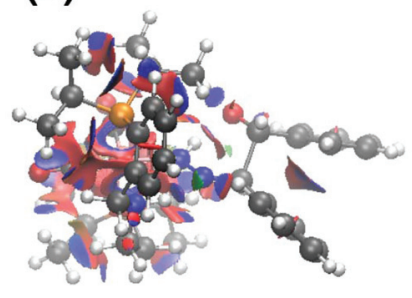

Fig. $6 \mathrm{NCl}$ plots for $\mathrm{F}-\mathrm{G}$ TSs in AF cycle, corresponding to: (a) $\left(S_{N}, S, S\right)$; (b) $\left(S_{\mathrm{N}}, S, R\right)$; (c) $\left(S_{\mathrm{N}}, R, S\right)$; and (d) $\left(S_{\mathrm{N}}, R, R\right)$ cases. The iso-surface represents a value of 0.5 with a colour scale for the reduced density gradient from -0.05 (red) to 0.05 (blue).

$[\mathrm{NHN}=\mathrm{CHPh}]^{-}$ligand on the metal moiety. The particular difference is in the $\pi-\pi$ stacking amongst the aryl rings, for which $\left(S_{\mathrm{N}}, S, S\right)$ shows the most attractive interaction, apart from the hydrogen bond between the keto group and the $\mathrm{NH}$ group, as well. Further, the most stable transition states, i.e., $\left(S_{\mathrm{N}}, S, S\right)$ and $\left(S_{\mathrm{N}}, S, R\right)$, also display another $\pi-\pi$ stacking inter- 
Table 1 Relative free energies (in kcal mol $\left.{ }^{-1}\right)$ for $\left(S_{N}, S, S\right),\left(S_{N}, S, R\right),\left(S_{N}, R\right.$, $S)$, and $\left(S_{\mathrm{N}}, R, R\right)$ TSs at different computational levels

\begin{tabular}{lllll}
\hline & $\left(S_{\mathrm{N}}, R, R\right)$ & $\left(S_{\mathrm{N}}, R, S\right)$ & $\left(S_{\mathrm{N}}, S, R\right)$ & $\left(S_{\mathrm{N}}, S, S\right)$ \\
\hline PBE0 + D3 & 3.4 & 6.2 & 0.9 & 0.0 \\
PBE0 & 3.0 & 7.4 & 2.8 & 0.0 \\
BP86 & 2.2 & 7.9 & 4.3 & 0.0 \\
BP86 + D3 & 2.8 & 5.8 & 1.1 & 0.0 \\
M06 & 2.7 & 6.6 & 3.0 & 0.0 \\
B3LYP + D3 & 2.9 & 6.2 & 2.1 & 0.0
\end{tabular}
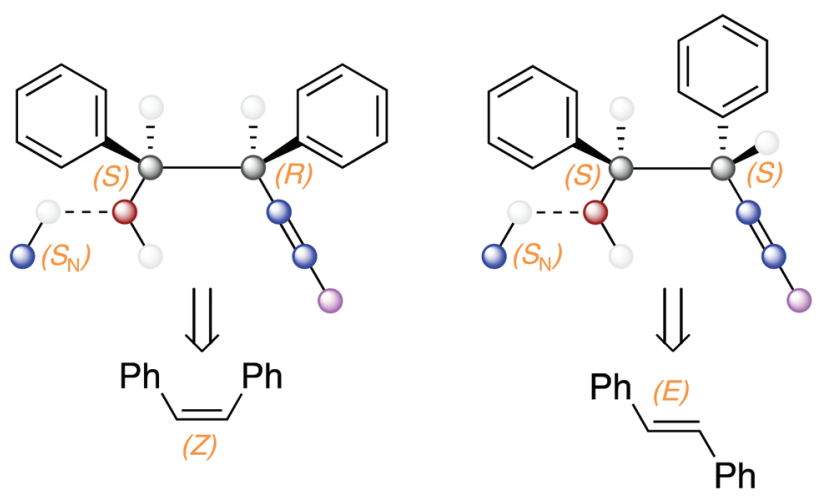

Scheme 2 Illustration of how $\left(S_{N}, S, R\right)$ and $\left(S_{N}, S, S\right)$ diazenyl intermediates will lead to cis- or trans-alkenes, respectively.

action between the aryl of the $[\mathrm{NHN}=\mathrm{CHPh}]^{-}$ligand and the annulated six-membered ring of the PNP skeleton.

Supporting calculations in which single-point energy refinement calculations were performed using a different functional, specifically PBE0, BP86, BP86 + D3, M06 (which already includes dispersion), and B3LYP $+\mathrm{D} 3$, show that $\mathrm{TS}\left(S_{\mathrm{N}}, S, S\right)$ is lower in energy than the rest in all cases (see Table 1). This unambiguously corroborates that kinetics control imposes selectivity towards the production of a trans olefin and that the results we have observed do not obey to DFT artefacts.

While decomposition of $\left(S_{\mathrm{N}}, S, S\right)$ and $\left(S_{\mathrm{N}}, R, R\right)$ diazenyl intermediates will lead to a trans-alkene formation, $\left(S_{\mathrm{N}}, R, S\right)$ and $\left(S_{\mathrm{N}}, S, R\right)$ cases will result in cis-alkene synthesis. Independently of the relative reaction free energies of the diazenyl intermediates, the kinetics control during the $\mathbf{F}-\mathbf{G}$ step imposes selectivity towards the formation of the $\mathbf{G}\left(S_{\mathrm{N}}, S, S\right)$ diastereoisomer. As seen in TS G-A, $\mathrm{N}_{2}$ and $\mathrm{H}_{2} \mathrm{O}$ release through proton transfer from the $\mathrm{N}^{*}(\mathrm{H})$ to $\mathrm{OH}$, regenerating the achiral 16e species $[\mathrm{Mn}-\mathrm{N}]$ and producing $(E)$-stilbene.

\section{Conclusions}

In summary, we have modelled in premiere the reaction mechanism for the unprecedented direct transformation of primary alcohols into alkenes catalysed by the most active $\mathrm{Mn}\left({ }^{\mathrm{i}} \mathrm{Pr}-\mathrm{PNP}\right)$ $(\mathrm{CO})_{2}$ amido catalyst, attending to Milstein's report. ${ }^{31}$ This consists in two main cycles. In the first, alcohol dehydrogenation (AD) into aldehyde takes place. The concerted mechanism has been calculated to be more favourable with a barrier of $16.1 \mathrm{kcal} \mathrm{mol}^{-1}$. Regeneration of the catalytic 16e species [MnN] by $\mathrm{H}_{2}$ elimination exhibits a barrier of $29.6 \mathrm{kcal} \mathrm{mol}^{-1}$, assisted by alcohol. In an excess of hydrazine, the already formed aldehyde converts into hydrazone. This can react with a second aldehyde molecule in a condensation process characterised to be diastereoselective towards the formation of a diazenyl intermediate. As shown in Scheme 2, while decomposition of the diazenyl intermediate with $\left(S_{\mathrm{N}}, S, R\right)$ [or $\left.\left(S_{\mathrm{N}}, R, S\right)\right]$ configuration would lead to a cis-alkene formation, the one with $\left(S_{\mathrm{N}}, S, S\right)\left[\right.$ or $\left.\left(S_{\mathrm{N}}, R, R\right)\right]$ configuration would lead to a transolefin. Tested with several methods, in all cases the $\left(S_{\mathrm{N}}, S, S\right)$ maximum exhibits the most favoured values of free energies, therefore rapidly decomposing into an $(E)$-alkene and liberating $\mathrm{H}_{2} \mathrm{O}$ and $\mathrm{N}_{2}$ as the only by-products.

Based on our mechanistic hypothesis, this represents the key step to understand the selectivity of these materials towards the generation of trans-olefins. Having solved the proposed mechanism, we strongly guess that our findings would stimulate further interests in the design of novel materials capable of catalyse the direct conversion of alcohols into alkenes at milder conditions.

\section{Conflicts of interest}

Authors declare no conflicts of interest.

\section{Acknowledgements}

L. M. A. is an ULPGC Postdoc Fellow, and thanks Universidad de Las Palmas de Gran Canaria (ULPGC). A. P. is a Serra Húnter Fellow, and thanks the Ministerio de Ciencia, Innovación y Universidades (MICINN) for project PGC2018097722-B-I00. We also acknowledge the KAUST Supercomputing Laboratory, using the supercomputer Shaheen II, for providing the computational resources.

\section{Notes and references}

1 A. Mukherjee and D. Milstein, ACS Catal., 2018, 8, 11435.

2 M. Garbe, K. Junge and M. Beller, Eur. J. Org. Chem., 2017, 4344 .

3 J. R. Carney, B. R. Dillon and S. P. Thomas, Eur. J. Org. Chem., 2016, 3912.

4 A. Nerush, M. Vogt, U. Gellrich, G. Leitus, Y. Ben-David and D. Milstein, J. Am. Chem. Soc., 2016, 138, 6985.

5 A. Mukherjee, A. Nerush, G. Leitus, L. J. W. Shimon, Y. Ben David, N. A. Espinosa Jalapa and D. Milstein, J. Am. Chem. Soc., 2016, 138, 4298.

6 M. Mastalir, M. Glatz, N. Gorgas, B. Stöger, E. Pittenauer, G. Allmaier, L. F. Veiros and K. Kirchner, Chem. - Eur. J., 2016, 22, 12316.

7 U. K. Das, Y. Ben-David, Y. Diskin-Posner and D. Milstein, Angew. Chem., Int. Ed., 2018, 57, 2179. 
8 T. P. Gonçalves and K.-W. Huang, J. Am. Chem. Soc., 2017, 139, 13442.

9 H. Li, T. P. Gonçalves, D. Lupp and K.-W. Huang, ACS Catal., 2019, 9, 1619.

10 S. Elangovan, M. Garbe, H. Jiao, A. Spannenberg, K. Junge and M. Beller, Angew. Chem., Int. Ed., 2016, 55, 15364.

11 S. Elangovan, C. Topf, S. Fischer, H. Jiao, A. Spannenberg, W. Baumann, R. Ludwig, K. Junge and M. Beller, J. Am. Chem. Soc., 2016, 138, 8809.

12 S. Elangovan, J. Neumann, J.-B. Sortais, K. Junge, C. Darcel and M. Beller, Nat. Commun., 2016, 7, 12641.

13 F. Kallmeier, T. Irrgang, T. Dietel and R. Kempe, Angew. Chem., Int. Ed., 2016, 55, 11806.

14 N. Deibl and R. Kempe, Angew. Chem., Int. Ed., 2017, 56, 1663.

15 A. Brzozowska, L. M. Azofra, V. Zubar, I. Atodiresei, L. Cavallo, M. Rueping and O. El-Sepelgy, ACS Catal., 2018, 8, 4103.

16 V. Zubar, Y. Lebedev, L. M. Azofra, L. Cavallo, O. El-Sepelgy and M. Rueping, Angew. Chem., Int. Ed., 2018, 57, 13439.

17 R. H. Crabtree, Chem. Rev., 2017, 117, 9228.

18 M. Mastalir, E. Pittenauer, G. Allmaier and K. Kirchner, J. Am. Chem. Soc., 2017, 139, 8812.

19 Y. K. Jang, T. Krückel, M. Rueping and O. El-Sepelgy, Org. Lett., 2018, 20, 7779.

20 S. Weber, B. Stöger and K. Kirchner, Org. Lett., 2018, 20, 7212.

21 N. Biswas, K. Das, B. Sardar and D. Srimani, Dalton Trans., 2019, 48, 6501.

22 J. C. Borghs, M. A. Tran, J. Sklyaruk, M. Rueping and O. El-Sepelgy, J. Org. Chem., 2019, 84, 7927.

23 J. C. Borghs, Y. Lebedev, M. Rueping and O. El-Sepelgy, Org. Lett., 2019, 21, 70.

24 F. Bottaro and R. Madsen, ChemCatChem, 2019, 11, 2707.

25 O. El-Sepelgy, E. Matador, A. Brzozowska and M. Rueping, ChemSusChem, 2019, 12, 3099.
26 A. Nodzewska, A. Wadolowska and M. Watkinson, Coord. Chem. Rev., 2019, 382, 181.

27 L. M. Azofra and L. Cavallo, Theor. Chem. Acc., 2019, 138, 64.

28 J. C. Borghs, L. M. Azofra, T. Biberger, O. Linnenberg, L. Cavallo, M. Rueping and O. El-Sepelgy, ChemSusChem, 2019, 12, 3083.

29 J. Masdemont, J. A. Luque-Urrutia, M. Gimferrer, D. Milstein and A. Poater, ACS Catal., 2019, 9, 1662.

30 J. A. Luque-Urrutia, M. Solà, D. Milstein and A. Poater, J. Am. Chem. Soc., 2019, 141, 2398.

31 U. K. Das, S. Chakraborty, Y. Diskin-Posner and D. Milstein, Angew. Chem., Int. Ed., 2018, 57, 13444.

32 G. Wittig and U. Schöllkopf, Chem. Ber., 1954, 87, 1318.

33 D. J. Peterson, J. Org. Chem., 1968, 33, 780.

34 M. Julia and J.-M. Paris, Tetrahedron Lett., 1973, 14, 4833.

35 A. D. Becke, Phys. Rev. A, 1988, 38, 3098.

36 J. P. Perdew, Phys. Rev. B: Condens. Matter Mater. Phys., 1986, 33, 8822.

37 F. Weigend and R. Ahlrichs, Phys. Chem. Chem. Phys., 2005, 7, 3297.

38 C. Adamo and V. Barone, J. Chem. Phys., 1999, 110, 6158.

39 S. Grimme, J. Comput. Chem., 2006, 27, 1787.

40 A. V. Marenich, C. J. Cramer and D. G. Truhlar, J. Phys. Chem. B, 2009, 113, 6378.

41 M. Valiev, E. J. Bylaska, N. Govind, K. Kowalski, T. P. Straatsma, H. J. J. Van Dam, D. Wang, J. Nieplocha, E. Apra, T. L. Windus and W. A. de Jong, Comput. Phys. Commun., 2010, 181, 1477.

42 E. R. Johnson, S. Keinan, P. Mori-Sánchez, J. ContrerasGarcía, A. J. Cohen and W. Yang, J. Am. Chem. Soc., 2010, 132, 6498.

43 J. Contreras-García, E. R. Johnson, S. Keinan, R. Chaudret, J.-P. Piquemal, D. N. Beratan and W. Yang, J. Chem. Theory Comput., 2011, 7, 625.

44 J. Poater, M. Gimferrer and A. Poater, Inorg. Chem., 2018, $57,6981$. 